\title{
A CIENTISTA E O ARTISTA: NISE DA SILVEIRA E ALMIR MAVIGNIER ENCONTRAM AS IMAGENS DO INCONSCIENTE ${ }^{1}$
}

\author{
José Otávio Motta Pompeu e Silva \\ Doutorando no Instituto de Artes da Unicamp
}

Neste artigo apresentado no III EHA da Unicamp em maio de 2007 apresento uma parte da dissertação de mestrado "A psiquiatra e o artista: Nise da Silveira e Almir Mavignier encontram as Imagens do Inconsciente". Focalizo a participação dos artistas Almir Mavignier, Ivan Serpa e Abraham Palatnik. Para recontar esta história utilizei entrevistas com pessoas que participaram do início deste ateliê, análise de gravações em vídeo do acervo do Museu de Imagens do Inconsciente, revisão bibliográfica, incluindo consulta a jornais e revistas da época.

A história do ateliê de pintura foi contada por Mário Pedrosa e por Nise da Silveira no livro Museu de Imagens do Inconsciente (1980). Elvia Bezerra (1995) contou esta história no livro A Trinca do Curvelo. Existem biografias de Nise da Silveira escritas por Ferreira Gullar (1996) e por Walter Melo (2001). O que poucos conhecem é a perspectiva dos artistas participantes dos primórdios do ateliê de pintura do Engenho de Dentro. A história deste ateliê teve uma origem incomum, talvez única na história das artes no mundo: quem montou de fato o ateliê de pintura dentro do hospital psiquiátrico foi um artista plástico.

Seu nome, Almir Mavignier ${ }^{2}$. Nascido no Rio de Janeiro a primeiro de maio de 1925, filho mais novo dentre quatro irmãos, sendo sua mãe de origem maranhense e seu pai paraibano, capitão de navio cargueiro do Lloyd Brasileiro. Almir Mavignier fez o curso ginasial e científico no Rio de Janeiro, onde prestou serviço militar, desenhando sem supervisão desde os tempos de ginásio. (MUSEU DE ARTE MODERNA DE SÃO PAULO, 2000, p. 12)

O jovem pintor autodidata, que trabalhava na parte de serviços burocráticos do hospital, no afã de dar vazão à sua arte, resolveu propor a montagem de uma exposição ou um ateliê de pintura à psiquiatra Nise da

\footnotetext{
${ }^{1}$ Este artigo foi originalmente apresentado na integra na dissertação de mestrado com o mesmo nome em 2006 no Instituto de Artes da Unicamp, para este artigo poderia também ser usado o título As Imagens do Inconsciente e a Arte Concreta no Brasil.

2 Pessoas com o sobrenome Mavignier foram citadas no livro Sobrados e Mucambos de Gilberto Freyre, aparecem na narrativa um médico e um artista com este sobrenome.
} 
Silveira que já desenvolvia várias oficinas de terapêutica ocupacional. A psiquiatra o atendeu prontamente e disse que só não tinha aberto ainda o ateliê porque não tinha funcionário para tanto. Almir Mavignier foi transferido para o incipiente setor de Terapêutica Ocupacional, com o apoio de Paulo Elejalde, diretor do hospital (MAVIGNIER, 2004).

Em uma verdadeira "arqueologia humana", Mavignier vasculhou os pátios do Centro Psiquiátrico Nacional, na época um complexo de hospitais psiquiátricos com mais de 2500 pessoas internadas, a procura de talentos artísticos; encontrou não mais que uma dezena de "colegas" que dividiram o ateliê de pintura no Engenho de Dentro. O jovem artista plástico Mavignier mergulhou no trabalho que realizava das 11 horas da manhã às 15 horas de segunda a sábado e forneceu instrumentos para os internos que sofriam de várias doenças mentais se expressarem. De uma forma sutil, oferecia materiais melhores para quem, em sua avaliação tinha um maior talento artístico. Relata em entrevista (Mavignier, 1989) que comprava com seu dinheiro telas cada vez melhores para Emygdio Barros, freqüentador do ateliê. Anos mais tarde o poeta e crítico de arte Ferreira Gullar intitulou Emygdio de Barros "como talvez o único gênio da pintura brasileira" e Mário Pedrosa levou as obras feitas fora do hospital por Emygdio de Barros para uma Bienal de Veneza, onde as obras foram expostas somente com o nome do artista, sem nenhuma alusão a doença mental.

Almir Mavignier, um artista plástico em início de carreira, de personalidade muito aberta e expansiva, convidou outros artistas e críticos de arte para conhecerem o trabalho realizado no ateliê de pintura do Engenho de Dentro. Impressionou-se com o resultado da produção plástica de seus colegas de ateliê. Escreve em uma correspondência com o autor em 2004: "os participantes do ateliê fizeram obras surpreendentes, que contribuíram para um ambiente fascinante de admiração e respeito".

Primeiramente Mavignier convidou Ivan Serpa que era seu amigo desde 1945, portanto antes de começar a trabalhar no ateliê de pintura do Engenho de Dentro. Almir conheceu Ivan Serpa em 1945 na Associação Brasileira de Desenho (modelo vivo). Também tiveram professores em comum Axel de Lescoschek e Heins Boese, em 1948 e 1949. (MAVIGNIER, 2004)

Outro jovem artista convidado por Mavignier foi Abraham Palatnik, logo que este voltou de Israel em 1947. Juntou-se a este trio o crítico de arte Mário Pedrosa que foi convidado no início de 1947 para visitar o Engenho de Dentro e nunca mais abandonou os artistas e as obras 
feitas lá. Mavignier nos conta que encontrou Mário Pedrosa na primeira exposição do ateliê no Ministério da Educação, em 1947. Pedrosa estava parado diante dos desenhos de Raphael. Mavignier que sabia quem era Mário Pedrosa, prontamente convidou o crítico para visitar o ateliê, e foi por seu intermédio que houve o encontro de Nise da Silveira com Pedrosa (MAVIGNIER, 2004). Esse encontro mudou a história do ateliê de pintura do Engenho de Dentro e propiciou a criação do Museu de Imagens do Inconsciente. Pedrosa foi o mais ferrenho defensor do que chamou posteriormente de arte virgem, que teve destaque na XVI Bienal de 1981.

Mavignier, Palatnik e Serpa, três jovens reunidos por laços de uma amizade e de atuação artística, tiveram um estranbo encontro no ateliê de pintura do Engenho de Dentro, marcando de alguma forma a história de vida e a obra de cada um desses grandes artistas brasileiros.

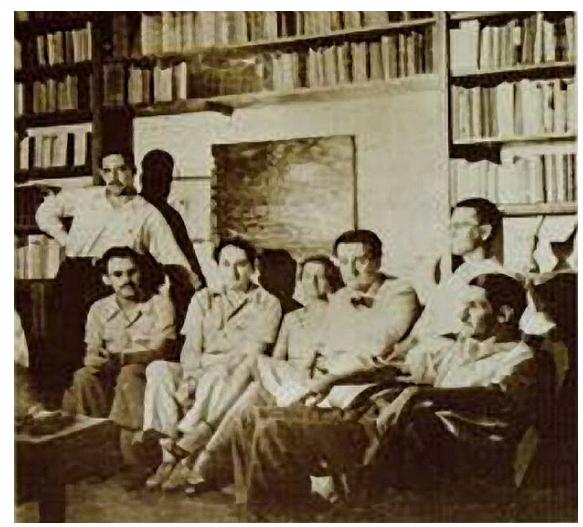

Figura 44

Residência de Pedrosa, RJ, 1951. Da esquerda para direita: Geraldo de Barros [em pé], Abraham

Palatnik, Mário Pedrosa, Lidy Pratt, Tomás Maldonado, Almir Mavignier e Ivan Serpa

Mário Pedrosa contribuiu de forma decisiva para colocar a produção plástica dos pintores do Engenho de Dentro no mesmo patamar de outras expressões artísticas contemporâneas como o abstracionismo e o concretismo, bem como da arte indígena e pré-histórica. No ano de 1995 o Museu de Belas Artes inaugurou a galeria Mário Pedrosa, utilizando uma pequena fatia desta idéia. Isso foi possível confirmar na exposição Brasil +500, que buscou reconstruir em uma exposição temporária o Museu das Origens idealizado por Pedrosa. A idéia central deste museu é a de preservação das obras e da identidade nacional. 
Mário Pedrosa era uma espécie de mestre dos três amigos Mavignier, Serpa e Palatnik. Quando tinham dúvidas ou angústias, dirigiamse para a casa do mestre e esperavam muitas vezes longas horas, pois este local era muito freqüentado por partidários de Pedrosa e a política era o principal assunto que ecoava pela casa. A espera era recompensada com as sempre inovadoras lições de arte do crítico.

Mavignier conta que "Palatnik, Pedrosa e Serpa estavam a par do que se passava no ateliê". Palatnik era quem mais freqüentava o ateliê, comparecendo todos os finais de semana, preferencialmente aos sábados. Suas palavras revelam a surpresa e perplexidade quando da sua primeira visita ao ateliê.

Eu sei que quando eu cheguei lá, eu vi que aquilo não podia ser um ateliê, era uma sala muito simples onde estava o Emygdio, o Carlos, o Diniz, o Isaac, a Adelina, estavam lá trabalhando; eu sei que eu fiquei chocado com aquilo, eu fiquei tão arrasado, porque afinal eles não passaram quatro anos de Escola de Artes, não passaram nem um dia, nem uma hora. E as obras fantásticas, de uma densidade, cores e eu comecei a logo me questionar, a minha atuação era de estímulos externos e eu senti que aquilo não tinha nada de externo, apesar que eram trabalhos figurativos, mas aquilo vinha assim de dentro, só podia ser assim tão atento, era de uma riqueza de imagens, mexeu ... Eu senti que meu castelo estava desmoronando. Eu senti isso. E eu não sei... De repente me deu assim uma sensação que eu tinha que abandonar a pintura, eu não podia mais pintar, não era verdadeiro, era tudo ilusão porque era tudo estímulos externos.[...] Conclusão, tinha que vir de dentro, agora eu era muito novo, eu tinha 20 anos, meu subconsciente era uma porcaria, não tinha nada para tirar de dentro, [...] com esta decisão, eu larguei a pintura, mas eu conheci o Mário Pedrosa. (Palatnik, 2003)

Percebemos neste depoimento a influência do ateliê no artista Palatnik, um ponto de transformação em sua obra.

$\mathrm{Na}$ época que conheceu Mavignier, Palatnik - nascido no Rio Grande do Norte em 1928 - era um jovem pintor recém chegado da Palestina, onde morou desde seus quatro anos e fez seus estudos primários e secundários. Estudou física e mecânica na escola técnica do Exército Inglês na Palestina, durante a II Guerra Mundial, especializando-se em motores de explosão. Acostumado a desenhar desde menino, na adolescência freqüentou durante quatro anos um Ateliê Livre de Arte na Palestina, onde teve aulas de desenho com modelo vivo, pintura e estética. (MORAIS, 1999)

Diante das obras dos freqüentadores do ateliê de pintura do Engenho de Dentro ele diz "meu castelo ruiu". Ao observar pela primeira vez trabalhos de Raphael ou as composições de Emygdio, Palatnik viu ruírem todos os seus conhecimentos, todas as certezas que obteve em quatro anos de um dos melhores ateliês livres de arte do mundo. 
Com esta afirmação Palatnik exemplifica em sua condição individual, muito do que estava acontecendo no mundo das artes naquela época. Cânones consagrados da arte, referência a questões de técnica, padrões de estética e beleza, estavam a desmoronar.

Levado por Mavignier à casa de Mário Pedrosa, Palatnik expôs o seu drama. Com sapiência e compreensão, Pedrosa riu e disse, segundo depoimento do próprio Palatnik (2003): "Ah Palatnik, não é o fim do mundo. É muito importante os artistas conhecerem outros aspectos da forma".

No momento em que Mário Pedrosa falou isso, Palatnik (idem) percebeu que a forma não é um aspecto tão simples. Pedrosa também emprestou livros e recomendou-lhe o estudo da psicologia da gestalt. É desta época a tese de doutoramente de Pedrosa (1947) em que ele introduz o pensamento da psicologia da forma (gestalt) no Brasil. Esta contribuição auxiliou-o a dar uma nova significação ao que havia ocorrido. Percebeu que podia retomar a arte, mas sem usar a representação aprendida nos anos de ateliê em Tel-Aviv. Palatnik mergulhou em outros aspectos da forma que não apenas a reprodução aprendida nos anos de ateliê livre de artes na Palestina.

Retomou seu conhecimento de mecânica e eletricidade. Dentro de um mês, ele se viu cercado de engrenagens, motores, articulações que começava a mexer. Palatnik sabia que era pintor, mas tinha tomado a decisão de não usar mais a tinta convencional. Nas palavras de Palatnik: "Descobri a cor luminosa, a luz e a sombra colorida: a cor projetada, fazendo uma sombra, outra cor iluminando a sombra, dando a ela uma nova tonalidade e movimento, através de engrenagens e articulações". (PALATNIK, 2003)

Estudando a teoria da gestalt, Palatnik percebeu que na pintura convencional, tudo era ilusão. Intuiu que todo o conhecimento aprendido na escola de belas artes eram representações da realidade. Essas representações usavam cores e formas que levavam a identificação de figuras e movimentos. Ele fez a difícil escolha de despojar-se das ilusões para mergulhar no território virgem e inexplorado do uso da luz em seu estado bruto em composições artísticas.

Depois de dois anos de pesquisas, criou em 1949 o Aparelho Cinecromático, uma experiência inaugural da arte cinética no mundo. O primeiro Aparelho Cinecromático foi denominado Azul e roxo em primeiro movimento e foi exposto na I Bienal de São Paulo, em 1951. Palatnik é 
considerado pelos historiadores desta arte como o pioneiro mundial do trabalho com luzes e movimento.

Os laços de amizade entre Mavignier, Palatnik e Serpa ultrapassaram as telas e pincéis. Serpa e Palatnik escolheram para esposas duas amigas em comum, inclusive a esposa de Palatnik foi apresentada na casa de Ivan Serpa no Méier, zona norte do Rio, por Ivan e Ligia Serpa. Palatnik casou-se com Lea Menlinscky em 8 de março de 1953. (OSORIO, 2004, p. 99)

Ligia Serpa, falecida em 2005, contou-nos em entrevista (SERPA, 2003) que o marido aprendeu, freqüentando o ateliê de pintura do Engenho de Dentro, que a arte tem que vir de dentro. Ele mergulhou no inconsciente para produzir suas célebres cabeças e quadros como Joana $d^{\prime} A r c$.

Nesta obras expressionistas, Ivan mergulhou no inconsciente, com um passe de ida e uma volta sempre difícil, como nos contou Lígia. Relatou que Ivan pintou Joana d'Arc em apenas um dia, sentado no chão da sala em estado de catarse, sem parar para nada.

O mesmo sentimento que tocou Palatnik, que vislumbrou uma grande qualidade e uma expressão verdadeira do inconsciente nas obras dos pintores do Engenho de Dentro, apossou-se de Ivan Serpa que anos depois deu materialidade para genuínas Imagens do Inconsciente, tornando-se um expressionista na qualidade e força da sua obra.

O pesquisador Hélio Márcio Dias Ferreira (1996) mostra a face expressionista de Ivan Serpa no livro Ivan Serpa, o expressionista concreto, definindo como "expressionista a manifestação artística na qual identificamos um agente muito forte na visão pessoal do criador. Não apenas uma força do interior para o exterior, mas um movimento que se revela interpretativo do objeto que ele vê e retrata. Isto se verifica em todos os períodos da História da Arte". Completa que desde as formas abstratas nas pinturas das cavernas, a Arte Negra, dos astecas, Maias e Incas; como também figuras disformes de El Greco e pinturas da fase de Goya temos demonstrações do expressionismo.

Mavignier (1989) levanta a hipótese de que alguns desenhos atribuídos a Raphael Domingues poderiam ter sido feitos por Ivan Serpa em suas visitas ao ateliê no final da década de 40 do século passado. Segundo Mavignier, Ivan Serpa nutria uma grande admiração pelos desenhos de Raphael, desenhos de bico de pena que algumas vezes Serpa copiou durante o tempo em que ficava no ateliê a convite de Almir Mavignier. Não conseguimos identificar esses desenhos no acervo do 
Museu de Imagens do Inconsciente. Em correspondência enviada a mim, Mavignier (2004) confirma a influência da obra de Raphael na arte de Ivan Serpa.

Ivan Serpa foi professor de alguns artistas como Darcílio Lima, Sebastião Barbosa e Mário Mendonça que foram encaminhados pela psiquiatra Nise da Silveira. Serpa os aceitava como alunos e através da arte auxiliava essas pessoas que haviam passado por experiências de cisão da personalidade. Darcílio Lima, depois do seu encontro com Ivan Serpa, alcançou carreira internacional.

Influenciado pelo contato com Mário Pedrosa e impregnado do espirito da sua época, Mavignier realizou uma exposição em 1951 com 15 variações do abstracionismo no MAM/SP.

Mavignier ficou até 1951 no ateliê de pintura do Engenho de Dentro. De lá partiu para a Europa primeiramente para uma bolsa de estudo, depois de um circuito por diversos países. Fixou-se em $\mathrm{Ulm}^{3}$ na Alemanha, onde estudou como aluno muito próximo de Josef Albers na Escola Superior da Forma (Hochschule fur Gestaltung). Hoje reside na cidade de Hamburgo. A pesquisadora e crítica de arte Araci Amaral afirma no catálogo da mostra Mavignier 75 que a experiência do artista no ateliê de pintura do Engenho de Dentro foi fundamental para sua formação; o próprio Mavignier reconhece o ateliê como sua grande escola. (MUSEU DE ARTE MODERNA DE SÃO PAULO, 2000, p. 7). Mavignier (2005) afirma: "Foi essa vivência do Engenho de Dentro que me influenciou muito, me marcou muito como professor, o meu conceito pedagógico é ajudar aos jovens a procurar sua própria personalidade"

\footnotetext{
${ }^{3}$ Ulm é a cidade natal de uma das mais importantes pessoas do século XX no mundo, Albert Einstein. Situa-se na margem direita do rio Danúbio, na fronteira entre os estados federais de BadenWürtemberg e Baviera. Do outro lado do rio, já na Baviera, estende-se a cidade gêmea de Neu-Ulm. A cidade conta com pouco mais de 115 mil habitantes. (fonte: Wikipedia)
} 

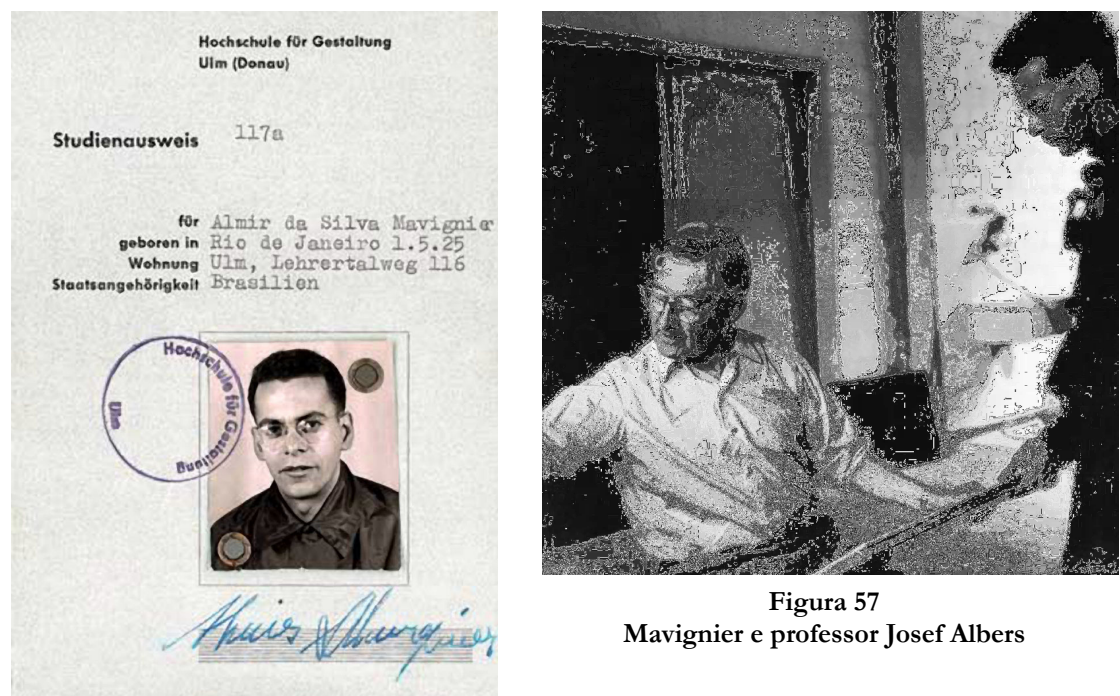

Figura 57

Mavignier e professor Josef Albers

Figura 56 - Carteira estudantil de Almir Mavignier na Alemanha

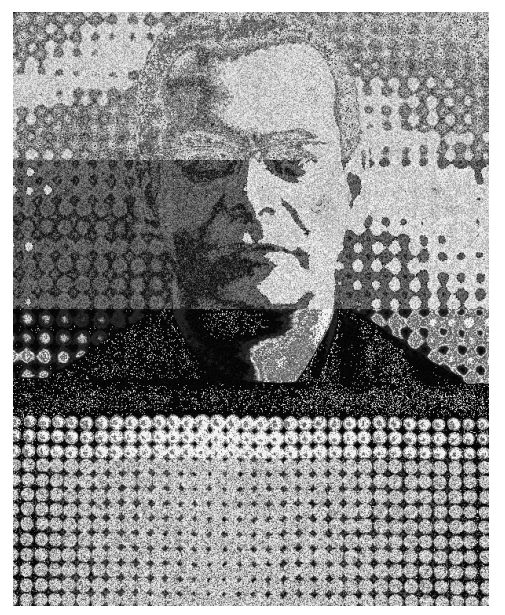

Figura 58

Foto de Mavignier

Fonte mavignier.com

\section{O ateliê de pintura do Engenho de Dentro e a arte concreta no Brasil}

A história contada neste texto traz um dado novo para entendermos a história da arte no Brasil. Almir Mavignier, Ivan Serpa e Abraham Palatnik se conheceram em outra circunstância, o primeiro ponto de encontro deles 
foi o ateliê de pintura do Engenho de Dentro. O encontro desses três jovens artistas com o crítico de arte Mário Pedrosa também aconteceu neste ateliê. Encontramos na fala de Abraham Palatnik, que diz que "seu castelo ruiu" a síntese do que aconteceu naquele momento. Os três jovens artistas contaminados com a experiência única de acompanhar obras "estranhas" aos cânones das artes emergirem de "loucos" internados em um hospital psiquiátrico, começaram a experimentar novas formas de "fazer arte" e em 1949 Mavignier começava a experimentar a produção de obras abstratas. Serpa liberava-se do figurativismo, iniciando desenhos ligados a obras infantis e partindo depois de alguns anos para o concretismo. Mas talvez a maior ruptura seria experimentada por Abraham Palatnik ao romper totalmente com o suporte da tela e dos pincéis, acabou sendo o percursor mundial da arte das luzes e dos movimentos.

Podemos pensar que um outro fator que influenciou estes jovens foi o que acontecia no Rio de Janeiro e no Brasil da época, onde pela primeira vez, exposições de vanguardas internacionais chegavam ao Brasil. No ano de 1949, o Ministério da Educação no Rio de Janeiro recebeu a exposição de pinturas abstratas Do Figurativismo ao Abstracionismo, exposição que também foi a inaugural do MAM/SP. Esta mostra foi organizada pelo crítico belga Leon Degand, primeiro diretor do MAM/SP. Reunia 51 artistas com 95 trabalhos ao todo, incluindo cinco telas de Wassily Kandinsky, e trabalhos de Alexander Calder, bem como três artistas brasileiros, entre eles Waldemar Cordeiro. A convivência com Mário Pedrosa trouxe novas idéias e colocou esses jovens na trilha da arte que era realizada no mundo. Diminuindo o abismo que existia entre o Brasil e o que acontecia na Europa e nos Estados Unidos. Podemos lembrar que o figurativismo era ainda hegemônico no Rio de Janeiro da década de 40 e quando se falava em ruptura, falava-se em movimentos que já tinham sido experimentados quase 40 anos antes na Europa como o Futurismo, Cubismo, Abstracionismo e outros. Era uma época de forte crítica de arte presente em páginas inteiras de todos os jornais de grande circulação e em várias revistas especializadas, com postuladores das vanguardas internacionais com Mário Pedrosa e de críticos mais conservadores como Quirino Campofiorito que promoveram verdadeiros debates de posições por meses a fio em suas colunas de crítica de arte. Trazemos aqui a constatação que a reunião dos três artistas no ateliê de pintura do Engenho de Dentro foi anterior da constituição Grupo Frente, ocorrido em 1954, no qual tanto Ivan Serpa, como Abraham Palatnik participaram. Levantamos que aconteceu uma via de mão dupla com as obras realizadas pelos internos 
do Engenho de Dentro influenciando as escolhas artísticas de Mavignier, Serpa e Palatnik e as informações trazidas pelas exposições da época e por críticos como Mário Pedrosa e Leon Degand influenciando a escolha do que era digno de ser exposto dentre a produção pictórica dos pintores do Engenho de Dentro.

Nesta mesma época um dos participantes do ateliê de pintura do Engenho de Dentro, Artur Amora, interno do hospital psiquiátrico, iniciava uma séria de seis telas onde sintetizava formas cada vez mais concretas, usando somente o preto e o branco em óleo sobre tela.

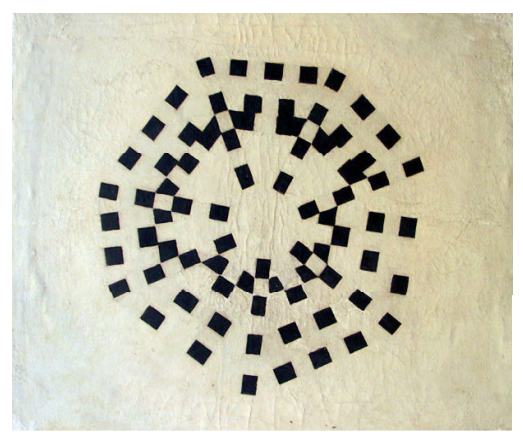

Figura 21

Sem título - Arthur

Amora 194? - óleo

sobre tela $-43 \times 53$

Como nos conta o próprio Mavignier (1994) a passagem de Arthur Amora no ateliê:

Teve uma breve passagem pelo Museu de Imagens do Inconsciente no final da década de 40, e não há maiores dados a seu respeito. Chegou ao ateliê desejando pintar, mas declarando que não sabia desenhar. Propus-lhe buscar um motivo que lhe interessasse. Descobriu uma caixa de dominós e copiou-os inteiramente. Depois, começou a simplificá-los, abandonando os pontos, e cobrindo as faixas brancas e pretas, rompendo os ângulos, encontrando curvas e criando estruturas de forte contraste ótico.

Considerava o branco e o preto como cores suficientes para seu trabalho. Dava títulos às composições com nomes de partituras musicais de Beethoven, Schubert, e Chopin. Porém recusava-se a mostrá-las a seus parentes, pois temia ser considerado perigoso. Queria voltar para casa. Produziu cinco óleos, quatro desenhos e projetos sobre papel. Depois, afastou-se do hospital. Suas composições em branco e preto foram realizadas aproximadamente entre 1949 e 1951 . Na mesma época, grupos de pintores auto-intitulados "concretos", influenciados pela pintura "concreta" suíça - de caráter geométrico -, discutiam no eixo Rio-São Paulo sobre quem seriam os pioneiros do movimento no Brasil. Os trabalhos de Amora revelam um geometrismo conseqüente e livre de influências estrangeiras.

Concluímos que o ateliê de pintura do Engenho de Dentro faz parte do mosaico da história da arte no Brasil e que seu estudo mais sistemático nas diversas fases pode trazer contribuições para reflexões interdisciplinares nos campos da arte, saúde mental, e educação. 


\section{Referências Bibiográficas}

BEZERRA. E. A trinca do Curvelo: Manuel Bandeira, Ribeiro Couto e Nise da Silveira. Rio de Janeiro: ToopBooks, 1995.193 p.

FERREIRA, H. M. D. Ivan Serpa: o expressionista concreto. Niterói: EDUFF, 1996.

GULLAR, F. Nise da Silveira. Rio de Janeiro: Relume-Dumara, 1996.

MAVIGNIER, A. Almir Mavignier: depoimento. Entrevistadora: Cristina Amendoeira. Hamburgo, 2005.1 mini-DV (60 min), color.

MAVIGNIER, A. Almir Mavignier: depoimento. Entrevistadores: Gladys Schincariol; Lula Vanderlei et al. Rio de Janeiro: Produção Museu de Imagens do Inconsciente, 1989, VHS (120 minutos), NTSC, color, som mono. Entrevista concedida ao grupo de estudos do Museu de Imagens do Inconsciente.

MAVIGNIER, A. Resposta de questionário proposto por J. O. Pompeu e Silva [correspondência postal]. Correspondência enviada em 28 jun. 2004.

MAVIGNIER, Almir. Museu de Imagens do Inconsciente. In: Museu de Imagens do Inconsciente. Catálogo da Exposição Brasil - Confluência de Culturas. Alemanha, 1994.

MELO, W. Nise da Silveira. Rio de Janeiro: Imago, 2001.

MORAES, F. Abraham Palatnik: retrospectiva. São Paulo: Itaú Cultural. 1999.

MUSEU DE ARTE MODERNA DE SÃO PAULO. Mavignier 75. São Paulo: MAM Ibirapuera, e Shopping Villa-Lobos, 2000. Catálogo. (Curadoria Aracy Amaral).

MUSEU DE IMAGENS DO INCONSCIENTE. Museu de Imagens do Inconsciente: catálogo. Rio de Janeiro, RJ, 1980. (Coleção Museus brasileiros, 2)

OSORIO, L. C. Abraham Palatnik. São Paulo: Cosac Naify, 2004, 216 p.

PALATNIK, A. Abraham Palatnik: depoimento. Entrevistador: J. O. Pompeu e Silva. Rio de Janeiro, 2003. 1 fita, mini DV (30 minutos), NTSC, color, som estéreo. 